\title{
Strategic Alignment IT-Business: Towards a Proactive e-Public Sector
}

\author{
Monica Henriques ${ }^{1}$, José Braga de Vasconcelos ${ }^{1,2^{*}}$, Gabriel Pestana ${ }^{1}$, Álvaro Rocha ${ }^{3}$ \\ ${ }^{1}$ University Europeia, Lisbon, PORTUGAL \\ ${ }^{2}$ University of Lisbon, Centre for Public Administration and Public Policies (CAPP), PORTUGAL \\ ${ }^{3}$ University of Coimbra, PORTUGAL
}

*Corresponding Author: jose.vasconcelos@universidadeeuropeia.pt

Citation: Henriques, M., de Vasconcelos, J. B., Pestana, G. and Rocha, Á. (2019). Strategic Alignment ITBusiness: Towards a Proactive e-Public Sector. Journal of Information Systems Engineering \& Management, 4(2), em0100. https://doi.org/10.29333/jisem/5932

Published: September 15, 2019

\begin{abstract}
The problem discussed in this paper is the paradox associated with hundreds of contributions of the scientific community over three decades, mainly leveraged by the Strategic Alignment Model (SAM) and its perspectives, but whose benefits arising from its applicability to the real world are scarce. The context of public sector organizations, which does not fit into any of the four perspectives presented by Henderson and Venkatraman (1993), led to the intertwining of the theme with Data Science. The hypothesis formulation involves interconnecting convergent concepts, namely through the adoption of a replicable framework in any world-wide public services, to potentiate the change of perspective, allowing to achieve the desired strategic alignment (IT-Business). It is hoped that the suggestions and recommendations can contribute to leverage significant changes in the Public Sector context in order to optimize the services provided, anticipating the citizen's needs.
\end{abstract}

Keywords: data science, information technology, public sector, strategic alignment

\section{INTRODUCTION}

Strategic alignment is a concept that is difficult to define. Depending on the context and the circumstances, it can assume multiple meanings, which makes it difficult to analyze and evaluate it.

Despite the visible effort of the scientific community to clarify the vision of strategic alignment (IT - business), there are still gaps in its applicability to the real world of organizations, because IT and business are inevitably very dynamic. Although there has been a high proliferation of contributions on this subject, the relationship between the premises and conclusions is losing consistency and coherence. Mostly because the proposed models prove to be too conceptual and dissociated from the practical reality of organizations. This leads some authors to question the validity and relevance of the link between business and IT, or whether it is still justified to continue to insist on revising and updating models that, in practice, prove to be so flat in terms of results.

The problem to be discussed is related to myopia (distorted vision) of the strategic alignment (IT-business). That is the paradox associated with hundreds of contributions of the scientific community over, at least, three decades, mainly leveraged by the Strategic Alignment Model (SAM), but the benefits resulting from its applicability to the real world are still scarce. Nonetheless, the theme remains a priority.

Data is a very valuable asset in decision support, and transparency enhances fact-based communication. However, each public sector organization tends to operate within its sphere of competence to achieve specific objectives, resulting in a gap from the global public sector point of view. 
Therefore, there is a long way to go in terms of optimizing service delivery, anticipating the needs of the citizens, using, in particular, analytical capacity.

The research methodology adopted follows the Design Science approach, based on a conceptual framework with seven Guidelines, which are: G1) Design as an artifact, G2) Problem relevance, G3) Design evaluation, G4) Research contributions, G5) Research rigor, G6) Design as a search process and G7) Communication of research (Hevner et al., 2004).

The main goal is to suggest the adoption of a meta-model, namely a Framework for e-Public Sector (G1). Assuming that the topic discussed is important and relevant to the business, the intention is to suggest the adoption of a technological solution in the area of Data Science (G2).

It's intended to demonstrate the utility, quality and effectiveness of the model through the application of a predictive model (G3). The objective here is to contribute with a replicable meta-model (Framework) in any worldwide public services (G4). It should allow the construction and evaluation of the proposed predictive model (G5). The use of Open Data and specific data analysis software aims to achieve the goal of using the means available to achieve the desired goal, i.e. problem solving (G6).

Finally, it is intended that the results and conclusions presented be effective for different audiences, as they are easily understood (G7).

The paper is organized into four sections. This section introduces the research issues for this study. The following section presents and discusses the concepts. Section III presents and discusses the results obtained with the study. And section IV is dedicated to the conclusions and recommendations for future work.

\section{BACKGROUND}

\section{Basic Concepts}

Alignment is not an innovative concept, having been discussed and documented several times since the late 1970s, e.g. McLean and Soden (1977) and ever since remained at the top of the concerns of organizational managers (Luftman, 2000).

The concept appeared mainly associated with the management, being sometimes accompanied or replaced by synonyms, such as fit, integration, bridge, harmony, fusion, and connection (Sun and Chen, 2008).

The term strategic alignment was initially used in strategic management before being extrapolated to the IT area, at a time when IT was no longer considered only as technology and became part of the whole organizational dimension, for performance and efficiency (Renaud et al., 2016).

Research conducted by MIT during the 1980s, served as an initial attempt to harness the strategic power of IT. Henderson and Venkatraman (HV) were influenced by this MIT'90 research program in the creation of SAM, which was developed with the contributions of two phases. The first is two working papers published in the context of the MIT' 90 and the second is the article published in the IBM Systems Journal. In the first two working papers, which are profoundly theoretical and conceptual (because they are devoid of empirical illustrations), the authors assume that SAM is a model for organizations in transformation, unfolding its descriptive and prescriptive role (Renaud et al., 2016).

This theme is regarded as a paradox. Despite the time devoted to their study, there are few empirical quantitative evidences about the factors that promote and maintain the alignment between business and IT, indicating that we know less than we should about the subject (Renaud et al., 2016). Still, according to the authors, it seems paradoxical, given the proliferation of articles that propose methods to achieve strategic alignment, or that identify factors that act as facilitators or inhibitors of this goal. Comparing the two initial articles (1989 and 1990) with the publication in 1993, there is a clear disconnection between the theoretical artifacts and their underlying assumptions and premises, thus giving freedom of interpretation and action to those who search them. According to them, the conditions of validity of the SAM do not fully meet the requirements of the intended contribution to the model.

As we can assume by the literature review, there is no shortage of criticisms of SAM, mostly because it is an extremely conceptual model that does not fit the real world of organizations and, as such, is difficult to use (Goepp and Avila, 2015). Even managers seem to know that this is by itself not enough to deal with the complexity of everyday business and because of that, the model is far from being implemented (Ciborra, 1997).

Despite the criticisms, the contribution of SAM, as well as those that have proliferated from it, are undeniable for the analysis of the problem.

\section{Strategic Alignment}

The proliferation of different, but empirically redundant, concepts may indicate the immaturity of discipline and consequently hamper scientific progress, leading to the degradation of the advancement and diffusion of knowledge in a particular area. In other words, according to this, without establishing what is being investigated, 
that is, the domain of a construct and its limits, as well as the dimensions and forms in which it occurs, it is not possible to develop empirical results and obtain comparable results (Moreno et al., 2014). As already mentioned, the literature reveals the lack of consensus regarding the definition of the strategic alignment concept (IT-business). Besides, there is also some fragility in the cause-effect relationships involving the construct. These shortcomings in theoretical efforts may explain the absence of quantitative empirical evidence, despite the relevance of the subject and the time elapsed since the researchers began to discuss it (Moreno et al., 2014).

A survey by the Society for Information Management has shown that strategic alignment (IT-business) remains a challenge for many organizations (Majstorović, 2016). Achieving and sustaining alignment (IT-business) remains a significant issue. IT investment has been increasing over the years as managers are looking for ways to successfully manage IT and integrate it into the organization's strategies. However, there are many variables. The technology and the business environments are very dynamic (Luftman, 2000).

Therefore, the alignment between business needs and IT resources remains a significant and worrying field. Moreover, the critical factor for a successful organization in a dynamic environment is an effective and efficient IT area that supports business processes and strategies (Silvius, 2007).

Initially, the IT area had a strictly business support function. However, with advances in technology, many have realized its potential in performing strategic functions. IT today is seen as interfering in the changing direction of organizations, including how they organize their business processes, how they communicate with customers, or how they deliver their products and services. In recent decades there have been several changes in the role of IT in organizations (Majstorović, 2016). The Internet, for example, allows organizations to create new outlets for their products or services, develop new services that affect retention and loyalty, and win new customers. That is, the IT area is changing organizations, becoming an instrument that develops and improves operations. As it is increasingly integrated, its change of role has resulted in a more significant impact in achieving alignment. Alignment is not a static or one-dimensional factor or process and is difficult to achieve (Majstorović, 2016).

\section{Strategic Alignment Model}

SAM, proposed by HV, is the best-known and most widely used strategic alignment model (Renaud et al., 2016). The first model of strategic alignment that gained the attention of practitioners and scholars was the HV model (Luftman et al., 2010). Since its introduction, it has been the focus of constant improvements. However, this and other models of strategic alignment are mainly descriptive, becoming very difficult to be applied by professionals, consultants, and researchers (Luftman et al., 2010).

Almost all models and consulting practices later in alignment start from this original model (Maes et al., 2000). Although they do not produce empirical evidence, nor do they provide a road map to assess and improve alignment, competitive advantage stems from the appropriate application of IT as a business strategy facilitator. The SAM model can be considered as a starting point for business alignment and IT models and frameworks. Although this model helps to understand the components that cause alignment, it does not provide the way or instructions to achieve alignment (Majstorović, 2016).

SAM has been the base for most of the strategic IT research that studies alignment and is empirically linked to business performance (Sun and Chen, 2008).

As the business environment is continuously changing and IT innovations are plentiful, strategic alignment should not be viewed as a state, but as a process of continuous change and adaptation over time, to optimize performance (Neubert et al., 2011).

In SAM, cross domain alignment is presented in two dimensions: strategic adjustment (between the external and internal domain) and functional integration (between the business domain and the IT domain). The purpose of this model is to provide a way to align IT with business goals to get value from IT investments. The authors argue that the potential strategic impact of information technology requires both the understanding of the critical components of IT strategy and the processes of adaptation and continuous change (Maes et al., 2000).

It is a conceptual model of strategic IT management, which describes business alignment and IT in two dimensions (Majstorović, 2016). The strategic adjustment differentiates an external focus, focused on the business environment and an internal focus, focused on the administrative structures. Thus, the strategic fit represents a vertical link, and functional integration represents the horizontal link. The model defines four key domains: business strategy, IT strategy, infrastructure, and organizational processes, as well as infrastructure and IT processes. Each domain has its components (Majstorović, 2016).

Connections in the SAM are essential because all quadrants and components must function as a whole. The strategic adjustment is the vertical link in the model, which explains the need for business decision-making and dictate its position in the market. Functional integration is the most directly related IT link and business alignment. As business changes, technology must change to keep up with business processes. This link describes the ability of the business to position itself successfully in the marketplace, leveraging the use of IT, which can bring a competitive advantage and maximize value (Coleman and Papp, 2006). 
The model was transformed into a management tool, in that alignment perspectives were created, resembling these to triangles. In this way, each perspective is composed of three components. The anchor is considered the most substantial area of the business. Changes in business are driven by this perspective. The pivot designates what will serve as support for the change, through realignment. Moreover, the area of impact is one that will be affected directly by the changes made in the pivot, through the realignment. Therefore, there is not a single strategic alignment, but a combination of strategic intra and inter-organizational alignments (Neubert et al., 2011).

However, since they are four quadrants, each one of them has three components, why do HV focus on only four perspectives, that is, half of those that could be analyzed and explored in the article in the end? The four perspectives only begin (are anchored) at the level of Strategy (business and IT). The remaining four are still to be explored, which can be initiated at the level of infrastructure and processes (organizational and IS).

That is, as Renaud et al. (2016) advocates, SAM was designed for high-level managers. However, a recurring issue is that, for the most part, the strategy is unknown or, in cases where it is known, it is uncertain and/or challenging to adapt (Chan and Reich, 2007). Besides, according to the authors, strategic choices made by an organization often result in imitation by other organizations. That is, given that the business environment and technology change so rapidly, once executed, there is a high probability that both are already obsolete (Chan and Reich, 2007).

As Silvius (2007) questions, with what 'business' should the IT area be aligned? According to the SAM, a first response should be the business strategy. However, in practice, business strategy, unfortunately, is not usually a clear target. Also, according to this, strategy provides a direction, not a destination (Silvius, 2007).

However, the authors safeguard that the future challenges are to deal with the selection of appropriate alignment perspectives, in addition to the four analyzed in the article. This argument requires that leaders consider a broader view of the potential role of IT within organizations (Henderson and Venkatraman, 1993).

\section{New Alignment Perspectives}

As a result, this contribution didn't take long to be published. Papp and Luftman (1995) explored the other four missing perspectives and added four more, resulting from the fusion between them. The eight different perspectives that can be formed from different combinations of SAM quadrants occur when strategic fit and functional integration are evaluated simultaneously. The four fusion perspectives result from the combination of the first perspectives, with the weakest pivot of the two being identified and treated first (Coleman and Papp, 2006).

\section{Social Era}

Pearlson et al. (2012) evidenced the evolution of the vision, over the last decades, of the use of information in organizations. Between the 1960s and 1990s the IT strategy was typically driven by business, inherent in the need for cost reduction. This IT support function already exists here, followed by the need to redesign business processes in order to create value. It is only in the last decade that organizations have begun to take advantage of the strategic opportunities of the so-called Social Era, which has made it possible to boost the evolution of IT platforms and resources in general. IT alignment to business decisions is no longer optional, it is imperative, given that organizations operate based on information (Pearlson et al., 2012).

Social era, mainly influenced by the emergence of social networks, is collaborative, people-driven or relationship-driven. Given the exponential use of smartphones, tablets, social tools, and Web-based businesses, some organizations limit themselves to using social IT as one-stop solutions to business opportunities. However, others even create a social business strategy, which analyzes the application of social IT tools and resources to seize business opportunities, giving rise to the concept of social organization (Pearlson et al., 2012).

Social networks thus offer the opportunity to find an entire network of individuals available to participate in organizational innovation processes at virtually no cost. Crowdsourcing, among others, started to be used by organizations that want to innovate, using social IT platforms to discuss new ideas with the public. Because the entire community can offer unique ideas, discuss trends, and vote on their preferences, such contributions increase the likelihood of business success. Adapting to this new reality naturally requires the redesign of business models and procedures to accommodate new experiences of relationships between the parties involved. Moreover, new uses of the Internet create new online business opportunities everywhere and without warning.

Therefore, there is also a tremendous impact on the professions, namely the extinction of those that can be automated and the birth of those that could not even be imagined. It is no longer surprising that a social IT native, who has already been born in a cyber world, surrounded by gadgets, has the ambition to be a YouTuber / Blogger / Influencer. The most popular channels have tens of millions of followers. Numbers of this order of magnitude reflect the influence among young people and adults, often serving as the main source of inspiration and entertainment. The number of views and likes, which, because they contain sponsor ads, turn out to be a highly 
profitable business, measures their success. Hotels, restaurants, airlines, travel agencies, or product brands are widely publicized and promoted by using social platforms.

Given the characteristics of these examples, the strategic alignment perspective fits into a bottom up approach, as opposed to the traditional top down advocated by HV. As such, it should have as a driver of change, or anchor, the infrastructure and IT processes, as it is considered the most active area. Moreover, the area of impact should be the business strategy, supported in the IT strategy. That is the perspective I/T infrastructure strategy.

\section{Hypothesis Formulation}

Data Science is an area of knowledge that has evolved with contributions from a wide range of academic fields, namely Mathematics, Engineering, Statistics, Computing, Data Structures and Algorithms, Artificial Intelligence, Machine Learning, among other things.

In past few years society has been witnessing an unbridled race to the ambitious digitization, which has provoked a substantial digital trail. The registration, storage, and management of citizens' preferences, habits and behaviors are invaluable to organizations, considering that this data has a high potential when analyzed and transformed into information and knowledge.

Organizations have for some time, been trying to get the most out of the value of data collected and stored about citizens, products, markets or processes. However, only recently are some of them able to excel through Data Science. According to Pearlson et al. (2012), one reason is that many organizations in many industries offer similar products and use comparable technologies. According to this, business procedures are among the last remaining points of differentiation. Building an environment that supports and encourages analysis is a critical component and this requires alignment of IT strategy and organizational strategy with business strategy. This includes aligning the organization's culture, incentive systems, metrics used to measure the success of initiatives and analytical processes, with the goal of creating a competitive advantage (Pearlson et al., 2012).

Therefore, organizations that gain competitive advantage from Data Science use analysis as a component that is considered an integral part of the business. According to the same author, leaders must move the company's culture towards an evidence-based management approach in which evidence and facts are analyzed as the first step in decision making. This evidence-based management encourages decisions based on data and analysis rather than on experience and intuition (Pearlson et al., 2012).

Such a scenario has only now become a reality due to the evolution of computing power (storage and processing capacity) and the reduction of hardware and software costs. It allowed the transfer of knowledge, purely academic (due to the high processing requirements), more specifically regarding the current implementation of algorithms in commercial software, completely revolutionizing this area. In practice, there is a reduction from four to six weeks to only a few hours.

It becomes necessary that faster analytics, which came with Big Data, is aligned with faster technology. An analysis that can take hours or days with transactional data and descriptive approaches is performed in seconds with Big Data technology. One of the peculiarities of data exploration is to find information initially unknown, and these findings of relations between variables and non-intuitive behavior or patterns are one of the promises of this technology (Larson and Chang, 2016).

Another example is e-participation, an emerging area that typically in the most recent research fields, does not yet have a very mature theoretical basis (Wirtz et al., 2018). According to the same authors, e-participation can be a crucial element of democratic societies, promoting citizen's confidence in the government, enhancing its legitimacy and improving government responsiveness. Moreover, based on increased opportunities using information technologies, e-participation should encourage a fair and efficient society and government (Wirtz et al., 2018).

Accountability and transparency are still essential factors for e-participation and are associated with some positive effects, being considered "pillars of the ideal democracy", as they increase citizens' confidence and can even reduce the corruption. New technologies, particularly those linked to social networks, facilitate online social interactions and contribute significantly to the creation and proliferation of such initiatives (Wirtz et al., 2018).

In this sequence, a Data Science process was developed, based on open-data datasets of different public sector organizations, whose results and conclusions will be discussed in the next section.

\section{RESULTS AND DISCUSSION}

Based on the survey of the State of the Art and the Research Methodology adopted, a descriptive and predictive analysis of the collected data was carried out.

There are numerous examples of life events that could be discussed here, as well as the positive and negative aspects associated with the citizens' experience when using a public service and for which improvements could be suggested. 
Table 1. Examples of Life Events in the context of Public Services

\begin{tabular}{ll}
\hline$\#$ & Life Event \\
\hline $\mathbf{1}$ & Birth / Marriage / Divorce \\
\hline $\mathbf{2}$ & Issuance / renewal of citizen's card or passport \\
\hline $\mathbf{3}$ & Enrollment in a public school \\
\hline $\mathbf{4}$ & Parental benefit / family allowance / school proof \\
\hline $\mathbf{5}$ & Associate household with family doctor \\
\hline $\mathbf{6}$ & Illness / Family Assistance \\
\hline $\mathbf{7}$ & Vaccination / family planning / pediatrics \\
\hline $\mathbf{8}$ & Issuance / renewal of driving license \\
\hline $\mathbf{9}$ & Registration of vehicles / building / commercial \\
\hline $\mathbf{1 0}$ & Tax \\
\hline $\mathbf{1 1}$ & Unemployment \\
\hline $\mathbf{1 2}$ & Retirement \\
\hline
\end{tabular}

However, for obvious reasons, only a few of them will be addressed, as an example of what is intended to be defended under this paper, but whose approach can be applied to any Public Sector (Table 1).

This study was based on Public Sector datasets, which are available to any citizen, in an Open Data and eparticipation approach, being able to access, analyze and reuse them, at any time, without any restriction or need for authorization.

The source of the data was, essentially, PORDATA, since it contains a panoply of aggregated data divided by themes, such as Population, Education, Health, Social Protection and Employment, among others.

These are still divided into sub-themes, such as: Teachers and Students, in the case of the Education.

In addition to allowing the visualization of the data in a table and graph, or the query of its meta information, the user also has the possibility to customize and filter their search, accessing the 'more options and data' and, in the end, export the result for .pdf or .xlsx.

The research can be carried out in 3 different repositories, according to the scope, that is, at the level of the municipalities, the country or the Europe (28 European Union countries or 19 Eurozone countries).

In addition to the features mentioned here, the user can also access publications, such as portraits that summarize some important indicators.

In this way, it was possible to query and extract enough data, which after selected, serialized and prepared for analysis. This data preparation phase proved to be quite time consuming, which was already expected in such a process.

A decade ago, one of the Administrative Modernization's key initiatives was the creation of the Citizen's Card, that allowed the unification of 4 different physical identification documents in the Portuguese Public Sector (Justice, Finance, Social Security and Health). This led to the digital simplification and dematerialization of processes, associated to the inclusion of new functionalities, through the electronic signature of documents or the possibility of online authentication.

The concept of Citizen's Shop which has been in existence for over a decade, has concentrated in one place several services of the Portuguese Public Sector, sharing resources and infrastructures (e.g. VoIP). Although it is a phased and evolving process, it is notorious the joint effort of Portuguese Public Sector services to provide a better citizens' experience.

However, despite the trajectory, a controversial aspect is the number of Portuguese Public Sector personnel. From the perspective of those who work there, given the apparent lack of substitution of human capital, which has since retired and, above all, due to the reduction in the number of people admitted, the functions that once were distributed by several people now accumulate. On the other hand, from the perspective of the taxpayer, the ideal would be that this number (and associated expenses) would effectively translate into full citizens' satisfaction, especially with the services provided by the Public Sector machine.

Starting with an analysis of some facts and taking as an example the Central Administration, the top 5 of the ministries with the highest number of employees, the top 3 of the ministries with the highest aging rates and how they are distributed among some professional groups.

The results show that while the top 4 of the ministries (Internal Administration, Science, Technology and Higher Education, Defense and Health) are between 30 and 50 thousand, approximately, the ministry of Education stands out, distanced, in the order of 170 to 200 thousand.

In another analysis, it is again the Ministry of Education that stands out the most, this time regarding the aging rate of its staff. In this case, with values that were around 850 effective and that have been increasing, already reaching more than 3150 employees with 65 or more years. It is also observed that, in the space of six years, the distance between the two other ministries (Health and Science, Technology and Higher Education) has been quite pronounced. 
Still another analysis shows that it is the professional group of teachers of pre-school, primary and secondary education that stands out more in relation to the distribution of staff, followed by health professionals (nurses, doctors, among others). In this sequence, analyzing in greater detail the Ministry of Education, particularly the reality of preschool and elementary education, teachers and students, public and private establishments, what do the data say?

It is verified that the distribution of the number of students enrolled in public education has increased slightly in the case of preschool, mainly due to legislative changes related to the beginning of compulsory schooling. In 2009 it went down from 6 to 5 and in 2015 to 4 years of age. As far as the 1st cycle of basic education is concerned, it is verified that since 1985 the number of students has been decreasing a lot.

However, by analyzing the distribution of the number of students enrolled in private education, there is greater stability compared to the first cycle of basic education, contrary to public education. And in the case of preschool, the trend is increasing, with the number of students almost doubling since 1987.

Regarding the distribution of the number of teachers, there is a great stability regarding preschool education. Regarding the 1 st cycle of basic education, the distribution of the number of teachers has fluctuated considerably over the years. In another analysis, it was also verified that between 1999 and 2009 the index of aging of preschool teachers and the 1st cycle of basic education, of public and private establishments, remained generally stable. However, since then, there has been a growing and rather marked trend in both cases.

Returning to the topic of the Public Sector Data Transparency and based on what has already been analyzed here, with a greater focus in the Education area, for the reasons listed, does the citizen have a clear idea of the functions that represent the highest expenditure of the Public Sector?

The results show that, although they are still in the top 3, the functions in the Education area are not currently those that represent the highest expenditure of the Public Sector. Since 2001, expenditures in the Education area have been exceeded by expenditures in the Health area and, later, in 2006, by the expenses in the Social Security area. Currently, the latter represents almost twice the education expenses. This leads to the need to look at data from different perspectives. To understand what led to the adoption of certain measures in time and justify moving in other directions.

Turning now to other important perspective, which is to analyze the reality from a macro perspective, what is the scenario of Portugal in Europe, namely the unemployment rate and the gross domestic product (\% of GDP) of the Europe Public Sector?

The results show that, currently, Portugal is still in the top 5 of the 28 countries of the European Union with the highest unemployment rate (from 15 to 74 years).

With numbers close to Croatia and Cyprus, followed by Spain and, lastly, at the top of the table, Greece. It can also be said that, in general, between 2008 and 2013 there is a growing trend, however, since that time it has been observed that the trend has reversed.

Regarding the Gross Debt, Portugal is in the top 3 of the 28 European Union countries with the highest gross debt (in \% of GDP) of the Public Sector, followed by Italy and Greece. At the bottom of the table is Estonia. Portugal shows a growing trend until 2014 and has remained stable since then. It is very interesting to note that Estonia has been able to remain stable over the last 23 years at the bottom of the table.

Based on the obtained results it was considered useful to analyze the successful case of Estonia.

For Estonia, e-Governance improves the country's competitiveness and increases citizens' welfare, particularly by keeping the Public Sector fully operational (24/7). This goal has become a reality because it is backed by digital identity, robust databases and secure exchange of personal data. Technological evolution, over the years, electronic voting system (i-voting) and Blockchain are just a few examples of what has become true for more than a decade in Estonia (e-Estonia).

The development of Estonia's e-Governance ecosystem was supported by strategic vision, citizen trust and cooperation with the technological sector.

Citizens have the right to know who uses their personal data, which is the cornerstone of trust in e-Governance. Applying the "ask once only" principle means citizens only need to send their data once to the Public Sector for use and reuse.

Currently $99 \%$ of public services are available to citizens as electronic services and Estonia is striving to provide proactive and invisible services by transmitting the efficient use of data that the Public Sector already has.

The concept of proactive e-Public Sector means an automatic provision of services, without the need to wait for citizens' requests (e-Estonia).

Following the discussion of these results, based on the descriptive analysis of the data, we proceeded to identify some aspects with potential for predictive analysis. Particularly those that may be associated with life events, the results of which trigger suggestions for actions that may improve citizens' experience in the Public Sector.

What is now meant to be exemplified is that a type of Life Event (Table I), namely \# 1 - Birth, whose data are transmitted to the Public Sector (Justice, in this case), may allow to predict other Life Events, such as the \# 5 - 


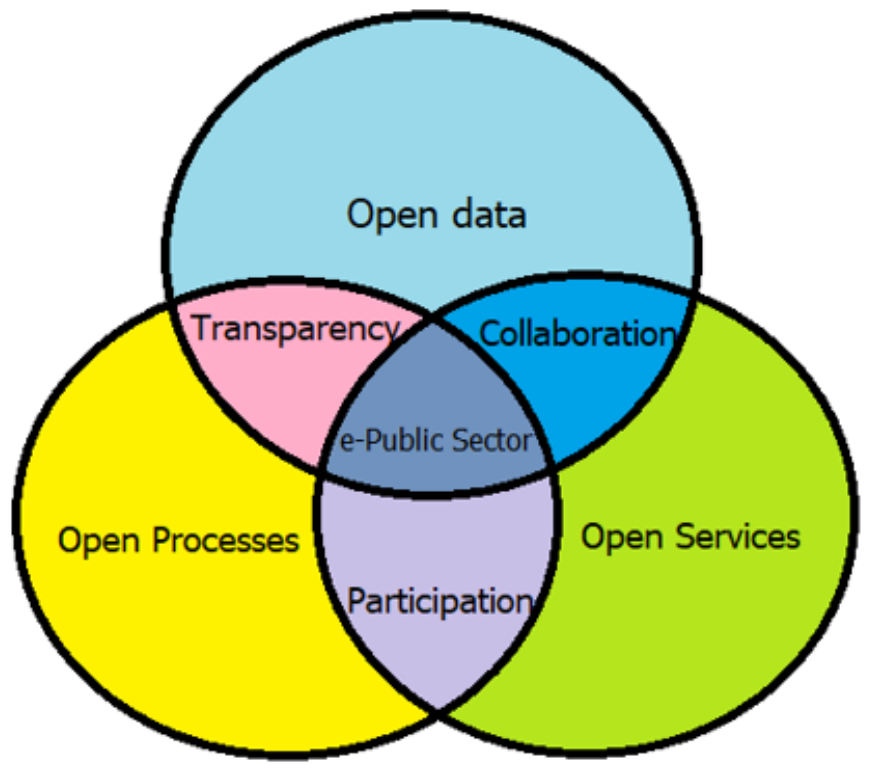

Figure 1. e-Public Sector Framework (Crowdpolicy - adapted)

associate household with family doctor or the \# 7 - vaccination or even later, the \# 3 - enrollment in a public school.

Although births in a certain place do not provide guarantees as to the habitual residence of the person born there, they may be at least indicative of the municipality or district to which they belong. Even so, after the birth, even if the address changes, the Public Sector keeps the track of the updates, via the digital identity, registered on the citizen's card.

This may allow the Portuguese Public Sector to care for, among other things, the provision of vaccine lots at health centers, the automatic attribution of the family doctor, or even the allocation of teachers from preschool education onwards, through number of students expected.

Although the current Public Sector scenario is extremely complex, yet it is quite challenging. A paradigm shift is evident, with an increasing focus on Administrative Modernization, processes automation, and the use of information technologies. However, given the lack of a global vision, in the context of strategic alignment (ITbusiness), it is urgent to implement solutions, namely using Open Data, e-participation and Predictive Analytics, to overcome this paradox.

This way, it is suggested to adopt a Framework for e-Public Sector (Figure 1), which should consist of the transparent and safe use of data and processes, the availability of user-friendly online public services, collaboration and active participation of citizens through the use of information technologies to ensure the efficiency and effectiveness of the entire ecosystem.

\section{CONCLUSIONS}

Based on literature review and analysis, we can conclude that the real world of organizations is full of factors that affect and condition the vision of strategic alignment (IT-business), causing myopia (distorted vision).

The issue remains a priority, although the paradox associated with the hundreds of contributions of the scientific community over at least three decades, mainly leveraged by the SAM, whose benefits resulting from its applicability are still scarce.

Hence the contribution of this research. Nowadays, or also called social era, it is possible to interconnect concepts that potentiate the change of perspective, allowing to achieve the desired strategic alignment (IT-business) in the organizational context.

Given its vast potential, Data Science is precious. Behavioral analysis, collected and stored over time, capture, among other aspects, the habits, routines, patterns, and feelings, considered normal or suspicious, of the citizens, often without their being aware of the size of the track they leave. Included in the digital track is, of course, the social component, directly associated with the virtual world, which scales and project the potential of Data Science to other levels.

For this reason, the theme is intertwined with e-participation, as it increases the confidence of citizens and involves them in decision-making. Although challenging, the proposal for change consists of altering the strategic 
alignment perspective adopted by most public sector organizations, so that they have the processes as a driver instead of the strategy.

In this way, the strategy will be supported by the knowledge obtained from the current social era, which, as we have seen, add value to organizations. That is the perspective I/T infrastructure strategy, framed in a bottom-up approach, as opposed to the traditional top-down advocated by HV. It is considered, therefore, that the arguments presented in this research serve the purpose of the study, since they guide future work in this area.

The next steps are to apply the concepts that have been discussed here to the Public Sector.

With the joint effort of the Public Services and with citizen's participation, one day the concept of proactive ePublic Sector will be a reality.

\section{ACKNOWLEDGEMENTS}

This research and resulting paper is supported by the Associação Ibérica de Sistemas e Tecnologias de Informação (AISTI) (Henriques et al., 2019).

\section{REFERENCES}

Chan, Y. and Reich, H. (2007). IT alignment: what have we learned? Journal of Information Technology, 22(4), $297-315$. https://doi.org/10.1057/palgrave.jit.2000109

Ciborra, C. (1997) De profundis? Deconstructing the concept of strategic alignment. Scandinavian Journal of Information Systems, 9(1), Art. 2.

Coleman, P. and Papp, R. (2006). Strategic Alignment: Analysis of Perspectives. Southern Association for Information Systems 2006 Proceedings, 42.

Crowdpolicy (n.d.). [Online]. Available at: https://crowdpolicy.com/

e-Estonia (n.d.). [Online]. Available at: https:/ / e-estonia.com/

Goepp, V. and Avila, O. (2015). An Extended-Strategic Alignment Model for technical information system alignment. International Journal of Computer Integrated Manufacturing, 28(12), 1275-1290. https://doi.org/10.1080/0951192X.2014.964774

Henderson, J. C. and Venkatraman, N. (1993). Strategic alignment: Leveraging information technology for transforming organizations. IBM Systems Journal, 32(1), 472-484. https://doi.org/10.1147/sj.382.0472

Henriques, M., Vasconcelos, J. B., Pestana, G. And Rocha, A. (2019). IT-Business Strategic Alignment in Social Era. In 2019 14th Iberian Conference on Information Systems and Technologies (CISTI), IEEE, pp. 1-6. https://doi.org/10.23919/CISTI.2019.8760883

Hevner, A. R., March, S. T., Park, J. and Ram, S. (2004). Design Science in Information Systems Research. MIS Quarterly, 28(1), 75-105. https://doi.org/10.2307/25148625

Larson, D. and Chang, V. (2016). A Review and future direction of agile, business intelligence, analytics and data science. International Journal of Information Management, $36(5), \quad 700-710$. https://doi.org/10.1016/j.ijinfomgt.2016.04.013

Luftman, J. (2000). Assessing Business-IT Alignment Maturity. Communications of AIS, 4, Art. 14. https:/ / doi.org/10.4018/9781878289872.ch006

Luftman, J., Dwivedi, R., Ben-Zvi, T. and Rigoni, E. H. (2010). IT Governance: An Alignment Maturity Perspective. Research Gate. https://doi.org/10.4018/jitbag.2010040102

Maes, R., Rijsenbrij, D., Truijens, O. and Goedvolk, H. (2000). Redefining Business-IT alignment through a unified framework. PrimaVera Working Paper Series.

Majstorović, M. (2016). Business and IT Alignment. Military Technical Courier, 64(2). https://doi.org/10.5937/vojtehg64-9263

McLean, E. and Soden, J. (1977). Strategic planning for MIS - A conceptual framework. The Academy of Management Review. https://doi.org/10.2307/257596

Moreno, V. A., Cavazotte, F. N. and Valente, D. O. (2014). Strategic Alignment and Its Antecedents: A Critical Analysis of Constructs and Relations in the International and Brazilian Literature. Journal of Global Information Technology Management, 12(2), 33-60. https:/ / doi.org/10.1080/1097198X.2009.10856490

Neubert, G., Dominguez, C. and Ageron, B. (2011). Inter-organisational alignment to enhance information technology (IT) driven services innovation in a supply chain: the case of radio frequency identification (RFID). International Journal of Computer Integrated Manufacturing, 24(11), 1058-1073. https://doi.org/10.1080/0951192X.2011.602363

Papp, R. and Luftman, J. (1995). Business and I/T Strategic Alignment: New Perspectives and Assessments. Americas Conference on Information Systems 1995 Proceedings, 46. 
Pearlson, K., Saunders, C. and Galletta, D. (2012). Managing \& Using Information Systems - A Strategic Approach (Sixth Edition). Wiley.

PORDATA (n.d.). [Online]. Available at: https://www.pordata.pt/

Renaud, A., Walsh, I. and Kalika, M. (2016). Is SAM still alive? A bibliometric and interpretive mapping of the strategic alignment research field. Journal of Strategic Information Systems, 25(2), 75-103. https:// doi.org/10.1016/j.jsis.2016.01.002

Silvius, A. (2007). Business \& IT Alignment in theory and practice. Hawaii International Conference on System Sciences. https://doi.org/10.1109/HICSS.2007.119

Sun, S.-Y. and Chen, Y.-Y. (2008). Consolidating the strategic alignment model in knowledge management. Int. J. Innovation and Learning, 5(1). https://doi.org/10.1504/IJIL.2008.015947

Wirtz, B., Daiser, P. and Binkowska, B. (2018). E-participation: A Strategic Framework. International Journal of Public Administration, 41(1), 1-12. https:/ / doi.org/10.1080/01900692.2016.1242620 